\title{
Assessment of Habitability of O-Age Red Sea Bream by Index Expression*1
}

\author{
Yoshiharu Matsumiya*2 and Tadashi Hattori*3 \\ (Received May 30, 1988)
}

\begin{abstract}
This study is to propose that comparative assessment is performed on the habitability of 0-age red sea breams as expressed in terms of unified indices. Relative condition index $y_{1}$ and density index $y_{2}$ are calculated using degree of fatness and distribution density in red sea bream caught by the fixed station. Habitability index $y_{3}$ is determined to $y_{1}+y_{2}$. The habitability at two bays of Hirado Island is assessed according to three kinds of indices. The inner bay areas in both the bays are ranked high in good agreement with past ecological studies. A multiple regression analysis is undertaken using $y_{1}, y_{2}$ and $y_{3}$ as criterion variables, and bottom materials, organic matter and feed biomass as explanatory variables. A considerable correlation is observed between three indices and the feed biomass variables, especially gammarids as a main food for red sea bream young.
\end{abstract}

A lot of valuable information has been accumulated from sea farming studies about ecology of 0-age red sea bream, Pagrus major, especially with respect to its habitat environments and food organisms. Currently, however, few of these studies are conducted from quantitative point of view, which limit their applicability.

In the present work, a comparative study was performed on the habitability of red sea breams, as expressed in terms of unified indices using degree of fatness and distribution density etc. in 0 -age youngs. Further, investigations were performed to uncover relationships which might exist between habitability and habit environments. ${ }^{1,2)}$ In particular, the influence on habit environment by gammarids, ${ }^{33}$ which have especially been known as a main food organism for red sea breams, was closely investigated.

\section{Material}

Zero-age red sea bream was caught in Shijiki Bay and Itoya Bay by experimental fishing carried out once a month during a period of June-August in 1976-1983 (Shijiki Bay) and 1981-1983 (Itoya Bay). Both bays are located in Hirado Island, Nagasaki Prefecture, Kyushu, Southern Japan. The fish caught was measured for its fork length (expressed in $0.1 \mathrm{~mm}$ unit, hereafter referred to as the length) and body weight (in $10 \mathrm{mg}$ unit, referred to as the weight). The number of the fish caught was analyzed by the fixed station and used as material.

The data relating to environmental factors used as material were collected in 1975 for Shijiki Bay, and in 1981 for Itoya Bay. The number of the fixed stations was 11 for Shijiki Bay, and 12 for Itoya Bay (Fig. 1). The red sea breams were caught with Gochi trawl (3-mm mesh net in the cod end). ${ }^{4}$ On the environmental data, only data of the biomass quantity of mysids was obtained with NUS-net $\left(0.5-\mathrm{mm}\right.$ mesh) ${ }^{5)}$ and the other data were obtained mainly with Smith-McIntyre $\operatorname{grab}\left(0.05 \mathrm{~m}^{2}\right)$.

\section{Methods}

\section{A Note on Relative Condition Index}

Two equations have been used to express length (L)-weight $(W)$ relationship: $W=A L^{3}$ and $W=$ $B L^{n},{ }^{\theta, 7)}$ Although $A$ (condition factor) is correct as an index to express absolute degree of fatness, a relative comparison is not possible if the threepower principle is not valid as $A$ becomes the function of the length. $B$ (relative condition index), on the other hand, can be used, after fixing the relative growth coefficient $n$ in accordance with the length, to compare the rela-

"1 The outline of this report was presented at the spring meeting of the Japanese Society of Scientific Fisheries, Takyo, April, 1984.

*2 Ocean Research Institute, University of Tokyo, Tokyo 164, Japan (松官義晴: 東京大学海洋研究所).

*9. Faculty of Fisheries, Nagasaki University, Nagasaki 852, Japan (服部唯史：舆崎大学水産学部). 


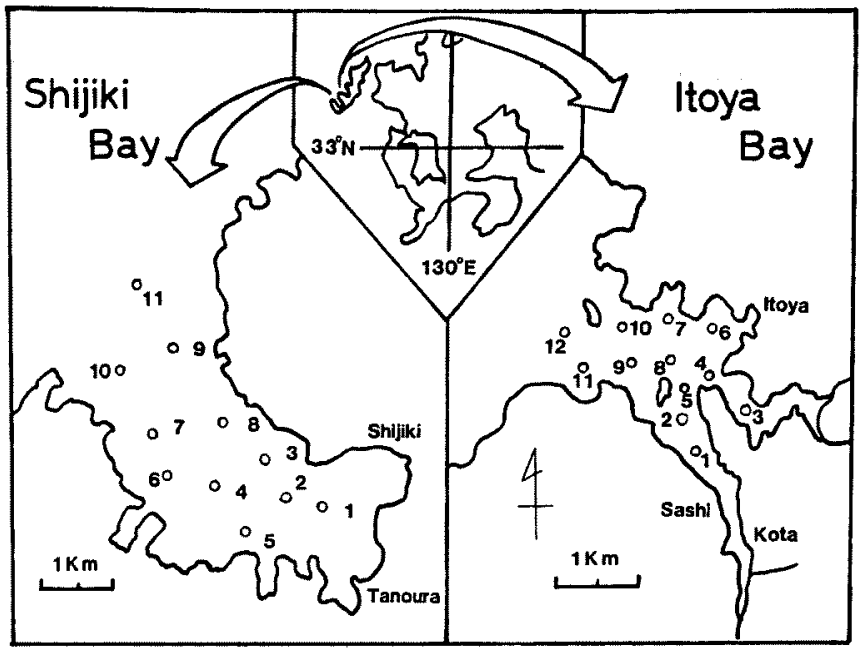

Fig. 1. Fixed stations in Shijiki Bay and Itoya Bay.

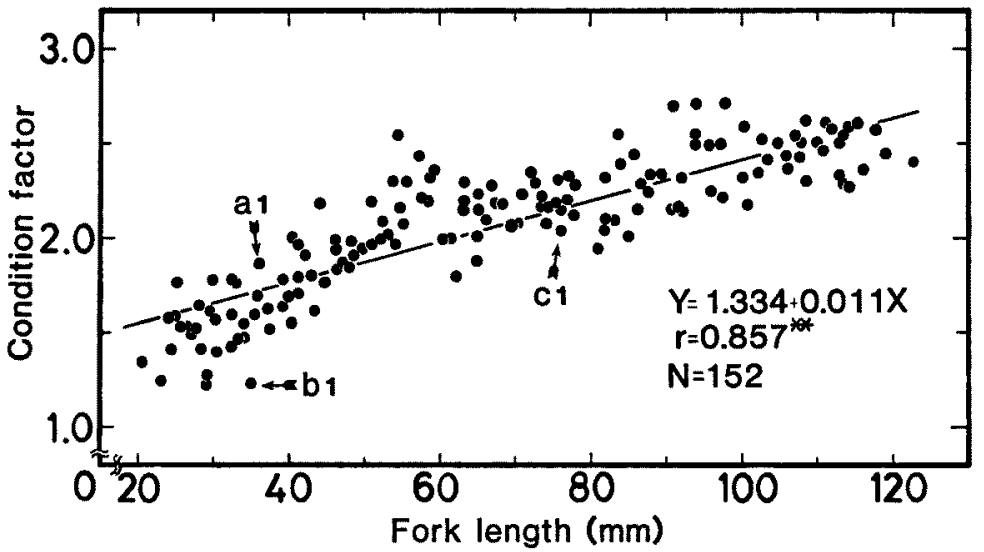

Fig. 2. Relationship observed in individuals of sea breams between their fork length and condition factor.

tive degree of fatness among individuals of different length. ${ }^{8,8)}$

Figs. 2 and 3 show the relationships observed in individuals of sea breams between their length and condition factor, and length and relative condition index, respectively. Data obtained in Shijiki Bay in 1982 is illustrated as an example. In this example, the condition factor $(A)=W(\mathrm{mg}) /$ $L^{3}(\mathrm{~mm}) \times 100$, and the relative condition index $(B)=W(\mathrm{mg}) / L^{n}(\mathrm{~mm}) \times 100$. The condition factor is expressed as a positive linear regression equation concerning the length, although no correlation exists between the relative condition index and the length.

As $A=B L^{n-3}$ and the value of the relative growth coefficient $n$ obtained for each year and month is in the range 3.1-3.4, the values of $A$ can not be used to compare difference between groups of different length. In Fig. 2, the relation among $a, b$ and $c$ was $c_{1}(2.01)>a_{1}(1.86)>b_{1}(1.22)$, while in Fig. 3, it has changed to $a_{2}(0.525)>c_{2}(0.434)>$ $b_{2}(0.348)$. The use of $B$ removes the effect of length, and, consequently, the individual $a_{2}$ having a greater degree of fatness at $30 \mathrm{~mm}$ length level exceeds the individual $c_{2}$ having smaller degree of fatness at $70 \mathrm{~mm}$ length level. No comparison can be made using the value of $A$ unless the length is identical (for example, individuals $a$ and $b$ ).

Sudo et al. ${ }^{102}$ have been assessing the habitability of red sea breams in Shijiki Bay using a ratio of carbon to nitrogen contents in the body $(C / N$ ratio) as indices expressing nutritive conditions of 


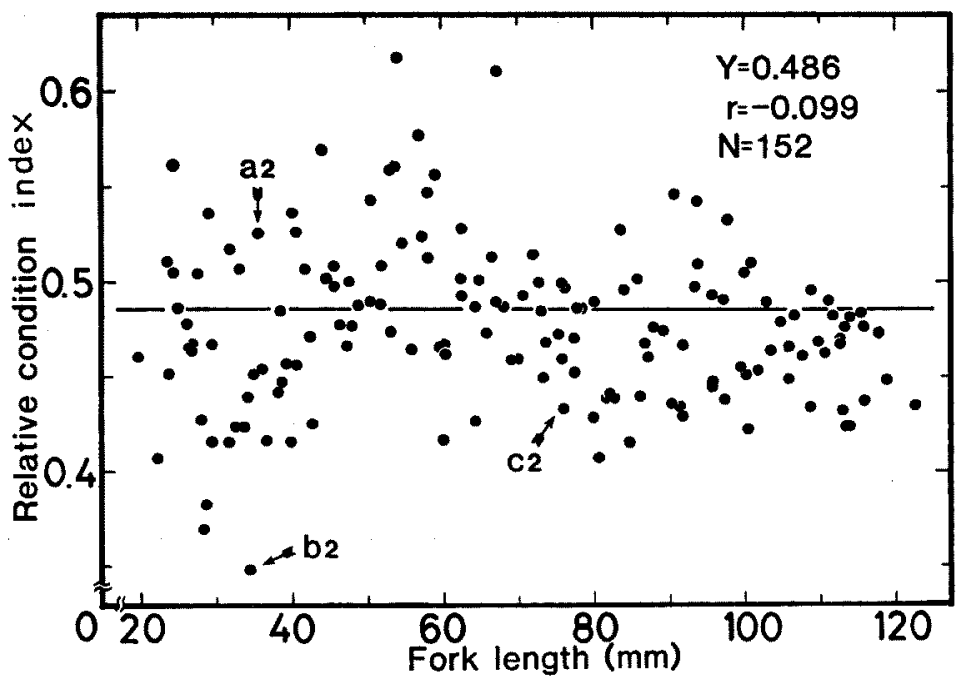

Fig. 3. Relationship observed in individuals of sea breams between their fork length and relative condition index.

the fishes. They determined the $C / N$ ratios of 45 red sea breams. We calculated the relative condition indices for all the individuals using their lengths, weights and relative growth coefficients. A statistically significant positive correlation $(P<$ 0.05 ) was observed between the $C / N$ ratios and the relative condition indices.

A statistically significant positive correlation $(P<0.05)$ was also observed between the relative condition indices calculated from wet and dry weights. This fact indicates that the relative condition index obtained from the wet weight which is assumed to be influenced by moisture contents, can be a good index to express the nutritive contions of the fish.

\section{Method to Calculate Indices}

The following calculations were conducted for each place, year and month of survey:

1) Relative condition index $y_{1}$ : Using all individuals caught, the relative growth coefficient $n$ is estimated from equation $W=B L^{n}$ using the linear regression $\ln W=\ln B+n \ln L$.* Then the relative condition index $B_{i}\left(=W_{i}\right)$ $\left.L_{i}{ }^{n}\right)$ is calculated for each individual to estimate mean relative condition index $B_{j}$ $\left(=\sum_{i=1}^{k} B_{i} / k ; k\right.$ represents the number of individuals) for each fixed station $j$. Mean $m\left(=\sum_{f=1}^{l} B_{j} / l ; l\right.$ represents the number of fixed station) of $B_{j}$ and standard deviation $s d$ are calculated to normalize $B_{j}$ using equation

$$
y_{1 j}=\left(B_{j}-m\right) / s d
$$

$y_{\mathrm{t}}$, a normalized value of $B_{j}$, was considered as a relative condition index.

2) Density index $y_{2}$ : The distribution density of red sea bream was chosen as an index for assessing its habitability. The number of red sea breams caught per Gochi trawl operation was normalized by a similar equation to equation (1) to calculate density index $y_{2 j}$. Most of the values obtained were in the region of $-2 \sim+2$, both $y_{1 j}$ and $y_{2}$, being 0 on the average.

3) Habitability index $y_{3}$ : A positive correlation generally exists between relative condition index $y_{1}$ and density index $y_{2}$, which indicates that summing up $y_{1}$ and $y_{2}$ makes the difference between habitats clearer. For this reason, $y_{1}+y_{2}$ was adopted as "habitability index $y_{3}$ ".

\section{Results and Discussion}

Assessment of Habitability by Index Expression

The fixed stations set in Shijiki Bay and Itoya Bay were ranked according to indices $y_{1}, y_{2}$ and $y_{3}$, for each year and month of survey. Further, the average monthly rankings of the fixed station were decided throughout the years of survey. Table 1 summarizes the results up to the third ranking.

* This estimation will be satisfactory if the variance of $\ln W$ is roughly constant. In Fig. 3 the errors seem to vary with length. This will have some effects on the validity of fitting the linear regression. 
Table 1. Average monthly rankings of the fixed stations throughout the years of survey for three indices in Shijiki Bay and ltoya Bay (the number of the fixed stations see Fig. 1)

\begin{tabular}{|c|c|c|c|c|c|c|c|}
\hline \multirow{2}{*}{ Index } & \multirow{2}{*}{ Month } & \multicolumn{3}{|c|}{ Shijiki Bay } & \multicolumn{3}{|c|}{ Itoya Bay } \\
\hline & & First & Second & Third & First & Sceond & Third \\
\hline \multirow{3}{*}{$y_{1}$} & June & 6 & 2 & 1 & - & - & - \\
\hline & July & 1 & 2 & 3 & 2 & 1 & 4 \\
\hline & Aug. & 2 & 5 & 3,8 & 10 & 3 & 2 \\
\hline \multirow{3}{*}{$y_{2}$} & June & 2 & 3 & 1 & 3 & 4 & 2,5 \\
\hline & July & 3 & 1 & 2 & 3 & 2 & 1,8 \\
\hline & Aug. & 1 & 3 & 2,5 & 3 & 2 & 6 \\
\hline \multirow{3}{*}{$y_{3}$} & June & 3 & 2 & 1 & - & - & - \\
\hline & July & 3 & 1 & 2 & 2 & 3 & 1 \\
\hline & Aug. & 3 & 1 & 2,5 & 1 & 3 & 2 \\
\hline
\end{tabular}

-: no data.

The average rankings for each month of survey in Shijiki Bay show a similar tendency for all three indices, i.e., fixed stations 1, 2 and 3, set at inner bay areas, ranked high in terms of all these indices. This result of the present study is in good agreement with a conclusion by Azeta et al., ${ }^{4)}$ Sudo et al., ${ }^{102}$ and Sudo and Azeta ${ }^{11}$ that the most favorable habitat for red sea breams in Shijiki Bay was considered, from their distribution, growth and nutritive conditions, to be on fine sand bottoms in inner bay areas, which are located near fixed stations 1 and 2 .

The result obtained for Itoya Bay, like that for Shijiki Bay, also shows that inner bay fixed stations 1,2 and 3 ranked high. Incidentally, these three stations are all on the fine-ultrafine sand bottoms.

When it comes to the ranking in terms of relative condition index $y_{1}$ in August, the fixed stations set in bay center or bay entrance areas ranked high in both Bays, suggesting well-fed red sea bream individuals, or their habitat itself that is favorable for them, moving or shifting from inner bay to bay entrance areas.

Investigation of Habitat Environments by Multiple Regression Analysis

A multiple regression analysis was undertaken using stepwise method $\left(F_{i n}=F_{\text {out }}=2.0\right)$, in which $y_{1}, y_{2}$ and $y_{3}$ were chosen as criterion variables, while the information, collected at the same fixed stations as shown in Table 2 , on bottom materials $\left(x_{1}-x_{8}\right)$, organic matters $\left(x_{8}-x_{7}\right)$ and feed biomass $\left(x_{8}-x_{10}\right)$, were chosen as explanatory variables. As for Itoya Bay, the regression analysis was undertaken using variables $x_{1}-x_{5}$ alone.

The monthly or overall results of the multiple regression analysis using 1976-1983's data for
Table 2. List of explanatory variables

\begin{tabular}{cl}
\hline Variable & \multicolumn{1}{c}{ Definition } \\
\hline$x_{1}$ & Depth $(\mathrm{m})$ \\
$x_{2}$ & Median diameter, $M d_{\phi}$ \\
$x_{3}$ & Coefficient of sorting, $S_{o}$ \\
$x_{4}$ & Coefficient of skewness, $S_{k}$ \\
$x_{5}$ & Mud content $(\%)$ \\
$x_{8}$ & Ignition loss $(\%)$ \\
$x_{7}$ & Total nitrogen $(\mathrm{mg} / 100 \mathrm{~g})$ \\
$x_{8}$ & Number of Polychaeta $\left(/ \mathrm{m}^{2}\right)$ \\
$x_{9}$ & Number of Mysidacea $\left(/ 15 \mathrm{~m}^{2}\right)$ \\
$x_{10}$ & Number of Gammaridea $\left(/ \mathrm{m}^{2}\right)$ \\
\hline
\end{tabular}

Shijiki Bay indicate a considerable correlation observed between all of the three criterion variables $y_{1}, y_{2}$ and $y_{3}$ and the feed biomass variables $x_{10}$ (gammarid biomass) and $x_{9}$ (mysid biomass). The multiple regression equation was found fit and statistically significant, the contribution amounting to $56-76 \%$ (Table 3 ).

However, for Itoya Bay using variables $x_{1}-x_{5}$ alone, no factors were found to have a clear correlation to the above three indices. Many of the multiple regression equations did not have a statistically significant regression.

Another multiple regression analysis was undertaken with total biomass of gammarids, the mainstay food for the 0 -age red sea breams in Shijiki Bay, as criterion variable, and with the biomass of the three species of them $\left(B_{j}, S_{m}\right.$ and $\boldsymbol{P}_{m}$ on Fig. 4 of Sudo et al. ${ }^{12)}$ ), which are taken as food in larger quantity than the other species, as explanatory variables. The result showed a significant correlation between the total biomass and the biomass of the three species of gammarids.

The purpose of the present work was not to examine the above described results in detail. No 
Table 3. Monthly and overall abstracts of the multiple regression analysis of Shijiki Bay

\begin{tabular}{|c|c|c|c|c|c|c|c|c|c|}
\hline \multicolumn{2}{|c|}{ Criterion variable } & \multicolumn{2}{|l|}{$y_{1}$} & \multicolumn{3}{|c|}{$y_{2}$} & \multicolumn{3}{|c|}{$y_{3}$} \\
\hline Month & $\begin{array}{l}\text { Explan- } \\
\text { atory } \\
\text { variable*1 }\end{array}$ & $\begin{array}{c}\text { Analysis } \\
\text { of } \\
\text { variance*2 }\end{array}$ & $\underset{(\times 100)}{\text { R-Square }}$ & $\begin{array}{c}\text { Explan- } \\
\text { atory } \\
\text { variable }\end{array}$ & $\begin{array}{c}\text { Analysis } \\
\text { of } \\
\text { variance }\end{array}$ & $\underset{(\times 100)}{\text { R-Square }}$ & $\begin{array}{l}\text { Explan- } \\
\text { atory } \\
\text { variable }\end{array}$ & $\begin{array}{l}\text { Analysis } \\
\text { of } \\
\text { variance }\end{array}$ & $\underset{(\times 100)}{\text { R-Square }}$ \\
\hline June & $x_{4}$ & - & 26.0 & $x_{10}$ & () & 73.6 & $x_{10}\left(x_{\theta}\right)$ & () & 69.6 \\
\hline July & $x_{10}\left(x_{0}\right)$ & 0 & 56.0 & $x_{10}, x_{\theta}$ & () & 76.4 & $x_{10}\left(x_{\theta}\right)$ & 0 & 59.4 \\
\hline Aug. & \multicolumn{2}{|c|}{ No Entering*s } & & $x_{10}$ & (C) & 74.0 & $x_{10}$ & 0 & 72.1 \\
\hline June & & & & & & & & & \\
\hline$\stackrel{\sim}{\text { Aug. }}$ & $x_{4}$ & 0 & 31.5 & $x_{10}$ & (อ) & 74.3 & $x_{10}$ & (a) & 64.0 \\
\hline
\end{tabular}

information enough to investigate is available in the present state of study. We consider it essential, first to obtain quantified data by expressing phenomena or observations in terms of wellcoordinated indices and analyze or arrange them, then to proceed to comparison, prediction or inference. Depending on circumstances, it is necessary to feed back this information to the examination on the propriety or reliability of the quantified indices themselves.

\section{Acknowledgements}

The materials used here had been obtained mainly by "Shijiki Group for Specieal Research on Red Sea Bream" and the Nagasaki Prefectural Fisheries Experimental Station.

To all the members, we wish to express our profound gratitude. We are particularly grateful to the following Dr. and Mr. for their kind guidance and collaboration: Masaru Tateishi, Yoshihiro Ikeda, Masao Oka, Masanori Azeta, Mikio Azuma, Masaru Tanaka, Katsuhiro Kiso, Fumihiko Kato, and Hiroyuki Sudo. We would like to thank Dr. G. A. F. Seber of the University of Auckland (New Zealand), and Mr. T. Akamine of the Japan Sea Resional Fisheries Research
Laboratory, for reviewing the manuscript and giving us the important advice.

\section{References}

1) H. L. Sanders: Limnol. Oceanogr., 3, 245-258 (1958).

2) D. C. Rhods: Oceanogr. Mar. Biol. Ann. Rev., 12, 263-300 (1974).

3) C. K. Biernbaum: J. exp. mar. Biol. Ecol., 38, 201-223 (1979).

4) M. Azeta, R. Ikemoto, and M. Azuma: Bull. Seikai Reg. Fish. Res. Lab., 54, 259-278 (1980).

5) M. Azuma, M. Azeta, and K, Mitsumaru: Bull. Seikai Reg. Fish. Res. Lab., 59, 101-118 (1983).

6) A. Ochiai: Nippon Suisan Gakkaishi, 18, 139146 (1952).

7) T. Ito: Nippon Suisan Gakkaishi, 19, 905-911 (1953).

8) E. D. Le Cren: J. Anim. Ecol,, 20, 201-219 (1951).

9) L. V. Piennar and J. A. Thomson: J. Fish. Res. Bd. Canada, 26, 123-131 (1969).

10) H. Sudo, R. Ikemoto, and M. Azeta: Bull. Seikai Reg. Fish. Res. Lab., 59, 71-84 (1983).

11) H. Sudo and M. Azeta: Bull. Int. North Pac. Fish. Comm., 47, 129-141 (1986).

12) H. Sudo, M. Azuma, and M. Azeta: Nippon Suisan Gakkaishi, 53, 1567-1575 (1987). 